\title{
Beta Spectrum Analysis: A New Method to Analyze Mixtures of Beta-Emitting Radionuclides by Liquid Scintillation Techniques
}

\author{
W. L. OLLER and P. PLATO \\ Department of Environmental and Industrial Health, School of Public Health, \\ University of Michigan, Ann Arbor, Michigan, U.S.A.
}

(Received 12 April 1972; in revised form 30 May 1972)

A description is given of a method to couple a liquid scintillation spectrometer to a multichannel pulse-height analyzer to record beta spectra simultaneously with three different energy ranges. Spectra of tritium, carbon-14 and phosphorus-32 recorded by this method are presented. Analyses of the beta spectra are performed by a least-squares technique, and the results are shown in tabular form.

\section{L'ANALYSE DES SPECTRES BETA: UNE NOUVELLE METHODE POUR ANALYSER LES MELANGES DE RADIONUCLEIDES EMETTEURS DE BETA PAR LES METHODES DE SCINTILLATION DE LIQUIDE}

On rend compte d'une méthode de relier un spectromètre à scintillation de liquide avec un analyzateur de hauteur de pulsations à multicanaux, afin d'enregistrer simultanément les spectres béta avec trois différentes gammes d'énergie. On présente les spectres de tritium, de carbone-14 et de phosphore-32 enregistrés par cette méthode. Les analyses des spectres béta s'achèvent par une méthode de moindres carrés, et on présente les résultats en forme de tableau.

$$
\text { АНАЛИЗ СПЕКТРА БЕТА-ЧАСТИЦ: }
$$

НОВЫЙ МЕТОД ДЛЯ АНАЛИЗА СМЕСЕИ БЕТА-ИЗЛУЧАЮЩИХ РАДИОИЗОТОПОВ ПРИ ПОМОЩИ ТЕХНИК ЖИДКОЙ СЦИНТИЛЛЯЦИИ

Дается описание метода соединения жидностного сцинтилляционного спектрометра c многоканальным амплитудным аналиватором импульсов, чтобы регистрировать спектры бета-частиц одновременно при трех разных диапазонах әнергии. Представлены спектры трития, углерода-14, фосфора-32, регистрированные әтим методом. Применится метод наименьших квадратов для анализа спектров бета-частиц, даны резултаты в виде таблиц.

\section{BETASPEKTRUMANALYSE: EIN NEUES VERFAHREN ZUR ANALYSE VON MISCHUNGEN VON BETASTRAHLER-RADIONUKLIDEN DURCH ARBEITSWEISEN DER FLUUSSIGKEITS-SZINTILLATION}

Es wird ein Verfahren beschrieben zur Kupplung eines Flüssigkeits-SzintillationsSpektrometers mit einem Mehrkanal-Impulshöhenanalysator, um Betaspektren gleichzeitig mit drei verschiedenen Energiegebieten zu registrieren, Mit diesem Verfahren aufgezeichnete Spektren von Tritium, Kohlenstoff-14 und Phosphor-32 werden vorgelegt. Die Betaspektren werden durch ein Verfahren der kleinsten Quadrate analysiert und die Ergebnisse in tabellarischer Form gezeigt.

\section{INTRODUCTION}

Considerable effort has been spent and continues to be spent on radiation monitoring in the environment around nuclear facilities, especially nuclear power reactors. As maximum allowable releases of radioactive wastes from nuclear reactors to the environment are reduced, emphasis will be placed on measurements made on reactor 
effluents to predict concentrations in the environment.

Quantitative analyses are made without difficulty on mixtures of gamma-emitting radionuclides with sodium iodide or germanium detectors provided that the concentration and gamma-ray abundance of each radionuclide are sufficiently large. However, standard procedures to analyze a complex mixture of radionuclides that emit beta particles as their primary or only mode of decay involve chemical separations to isolate all isotopes of a given element present in a sample followed by an analysis for total beta activity. ${ }^{(1)}$ These procedures are accurate in most cases although they are usually timeconsuming and expensive. Quantitative results are difficult to interpret for elements such as strontium where strontium-89, strontium-90 and yttrium-90 are present in various proportions. Table 1 contains a list of radionuclides

TABLE 1. Pure beta-emitting radionuclides observed by KAHN et al. ${ }^{(2)}$ in main coolant water and waste tank of a pressurized water reactor

\begin{tabular}{ccc}
\hline Radionuclide & Half-life & $\begin{array}{c}\text { Maximum beta } \\
\text { energy }(\mathrm{keV})\end{array}$ \\
\hline H-3 & $12 \cdot 3 \mathrm{yr}$ & $18 \cdot 6$ \\
C-14 & $5730 \mathrm{yr}$ & 156 \\
P-32 & $14 \cdot 3$ days & 1710 \\
S-35 & 88 days & 167 \\
Kr-85 & $10 \cdot 8$ yr & 670 \\
Sr-89 & 53 days & 1460 \\
Sr-90 & 28 yr & 546 \\
Y-90 & 64 hr & 2270 \\
\hline
\end{tabular}

that may be considered pure beta emitters and are present in the liquid effluents of nuclear power reactors.

A quantitative method to analyze samples that contain mixtures of beta-emitting radionuclides has been developed.* The method requires two analytical instruments commonly found in radiochemistry laboratories; a liquid scintillation spectrometer and a multichannel pulseheight analyzer. A spectrum of beta energies from a sample that contains a mixture of radionuclides is detected by the liquid scintillation spectrometer, recorded by the pulse-height

* This work was made possible by a research grant from the American Electric Power Service Corporation. analyzer, and resolved by a least-squares technique into component beta spectra.

Liquid effluent samples from nuclear power reactors contain different radionuclides; some emit only beta particles while others emit both beta particles and gamma rays. A complete isotopic analysis would require gamma spectrum analysis, beta spectrum analysis and other analytical procedures. This paper describes the instrumemtation and the techniques used to record beta spectra.

\section{INSTRUMENTATION}

A Packard 3380 liquid scintillation analyzer (LSA) and a Packard 901 multichannel analyzer (MCA) were used in this investigation. The LSA has three independent single-channel analyzers that permit one, two or three radionuclides of known identities to be used simultaneously in tracer studies. Each single-channel
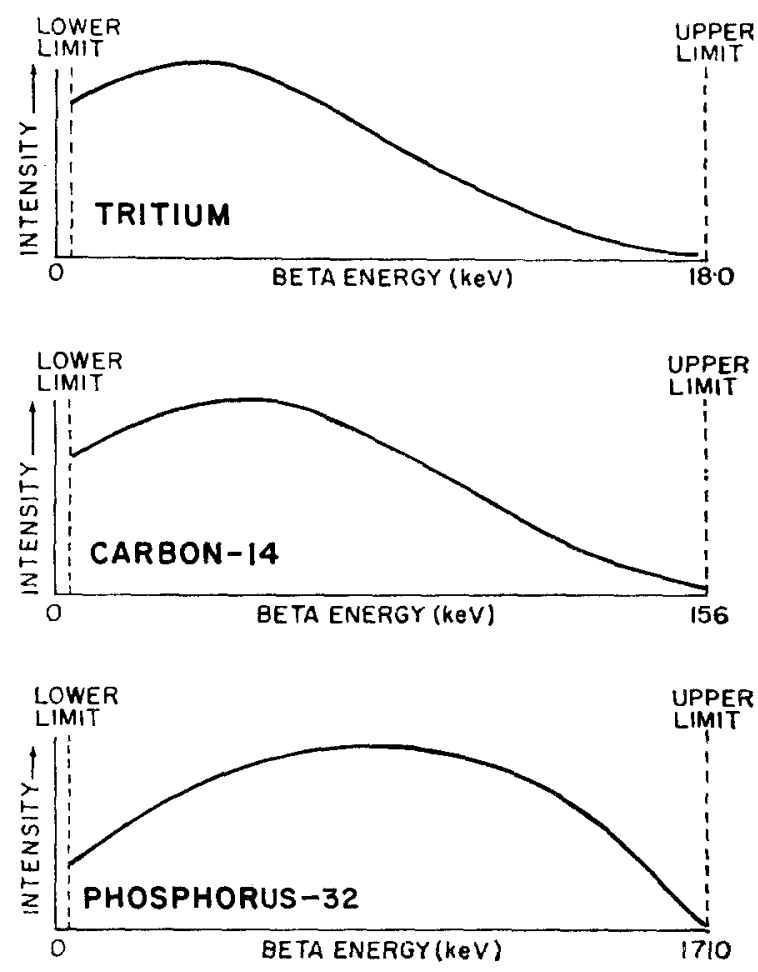

Fig. 1. Beta spectra of radionuclides with different maximum energies that are amplified to the upper limit of each discriminator in the three single-channel analyzers of the liquid scintillation analyzer. 


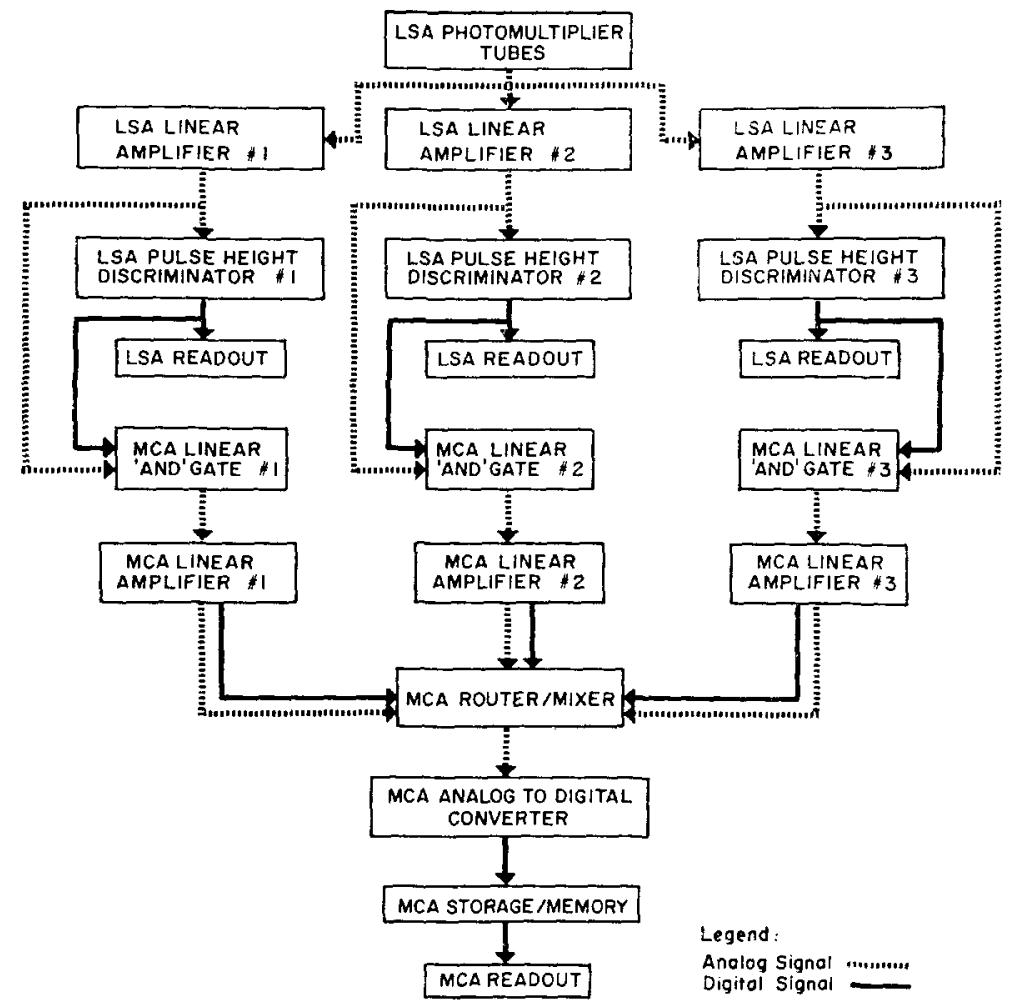

FIG. 2. A block diagram that shows how the liquid scintillation analyzer (LSA) is coupled to the multichannel analyzer (MCA) with the ancillary equipment.

analyzer has a linear amplifier with a lower and an upper energy discriminator. The gain of each amplifier is adjusted so that the upper discriminator limit of its single-channel analyzer corresponds to the most energetic beta particle emitted by a specific radionuclide. This provides better counting statistics than if equal amplification were used for radionuclides with different energies. However, if each single-channel analyzer were coupled to an MCA to record beta spectra and each radionuclide were amplified to the upper discriminator limit, the spectra displayed would appear similar to each other. The different amplification of each single-channel analyzer compensates for the energy differences among the radionuclides used and causes their beta spectra to appear similar. Figure 1 shows the similarities among the spectra of tritium, carbon-14 and phosphorus-32 that were amplified to the upper discriminator limit, but which have maximum beta energies of $18 \cdot 6$, 156 and $1710 \mathrm{keV}$, respectively.
Identification of unknown radionuclides recorded with a constant amplification would be difficult if not impossible. For instance, if one single-channel analyzer with amplification for phosphorus-32 were used to record tritium, the tritium spectrum would occupy only $l \cdot 1$ per cent of the phosphorus-32 spectrum which would make a quantitative analysis for tritium inaccurate. Therefore, a different method is required to perform spectrum analysis on beta emitters that have energy differences as large as tritium and phosphorus-32.

Figure 2 shows a block diagram of the method used in this investigation to couple the LSA to the MCA. The ancillary equipment necessary consists of three Packard 969 linear amplifiers with modified linear "and " gates and a Packard 966 four-signal router/mixer.

Each single-channel analyzer of the LSA receives an analog signal from the photomultiplier tubes that is proportional to the energy of the beta particle detected. The analog signal 


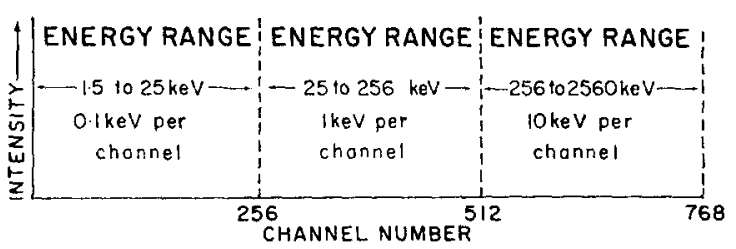

Fig. 3. The three energy ranges used to produce each beta spectrum.

is amplified and routed to the lower and upper discriminators. If the analog signal passes the discriminators, a digital signal is generated and used to drive a scaler and/or a ratemeter. The analog signals from each LSA amplifier are routed to the linear "and" gate of the corresponding MCA linear amplifier. All three linear gates of the MCA amplifiers receive an analog signal, but a digital signal from an LSA single-channel analyzer must be present simultaneously for a gate to pass the analog signal to the MCA linear amplifier. The MCA linear amplifier then amplifies the analog signal, generates a digital signal, and passes both signals
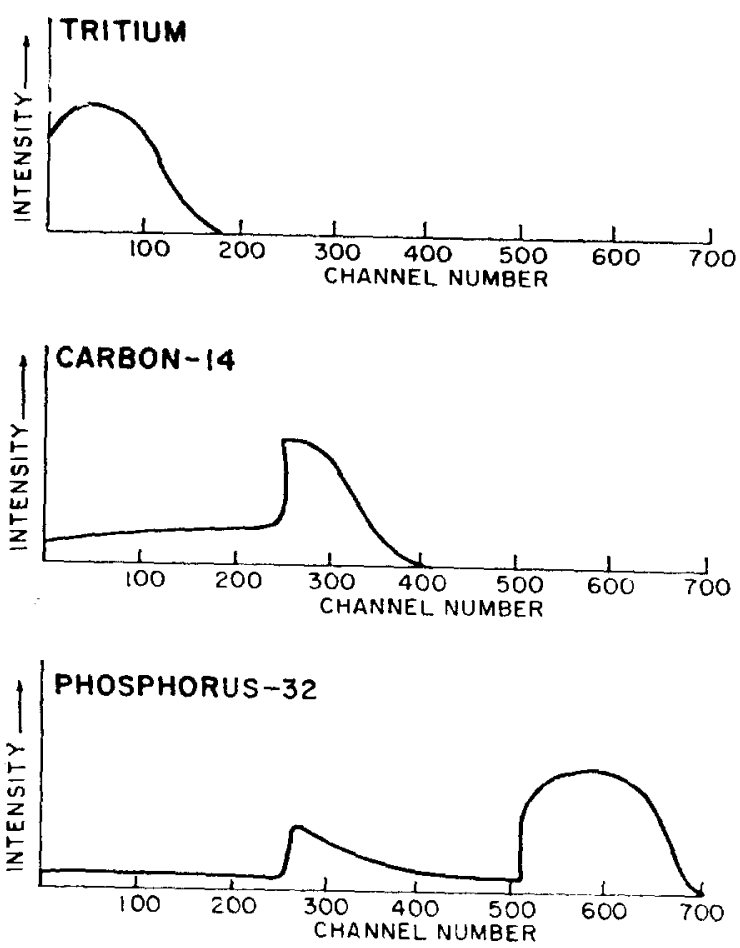

Fig. 4. Beta spectra of radionuclides recorded by the method developed in this investigation. simultaneously to the router/mixer. The digital signal is used by the router/mixer to identify the quarter of the MCA memory where the analog signal is to be stored.

This configuration of the equipment produces a single spectrum composed of three energy ranges. Each energy range consists of 256 channels with energy scales of $0 \cdot 1,1$ and $10 \mathrm{keV}$ per channel as shown in Fig. 3. The lower discriminator for each energy range is set above the maximum energy recorded in the previous energy range. Beta spectra are recorded in channels $15-768$ which corresponds to energies of $1 \cdot 5-2560 \mathrm{keV}$. The three energy ranges that the spectrum contains are used to describe the beta emitter irrespective of its maximum energy.

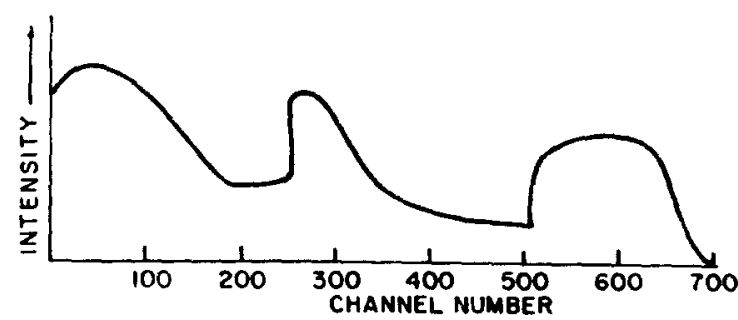

Fig. 5. A composite beta spectrum of a single sample that contains tritium, carbon- 14 and phosphorus- 32 recorded by the method developed in this investigation.

Interference from a radionuclide with a high maximum beta energy in a spectrum produced by a radionuclide with a low maximum beta energy is minimized with this method. Figure 4 shows beta spectra recorded by this method for tritium, carbon-14 and phosphorus-32. Figure 5 shows a beta spectrum recorded from a single sample that contained tritium, carbon-14 and phosphorus-32.

\section{RESULTS}

Initial investigations were performed with tritium, carbon- 14 and phosphorus- 32 to determine the feasibility of beta spectrum analysis as an analytical technique. Test samples were prepared with various combinations of these three radionuclides in known concentrations with a constant quench, and a beta spectrum of each sample was recorded and analyzed. A least squares spectrum analysis computer program was used to predict the activity of each radionuclide in each sample. Table 2 shows data 
TABLE 2. Comparison of actual activities of tritium, carbon- 14 and phosphorus-32 present in test samples with activities predicted by beta spectrum analysis

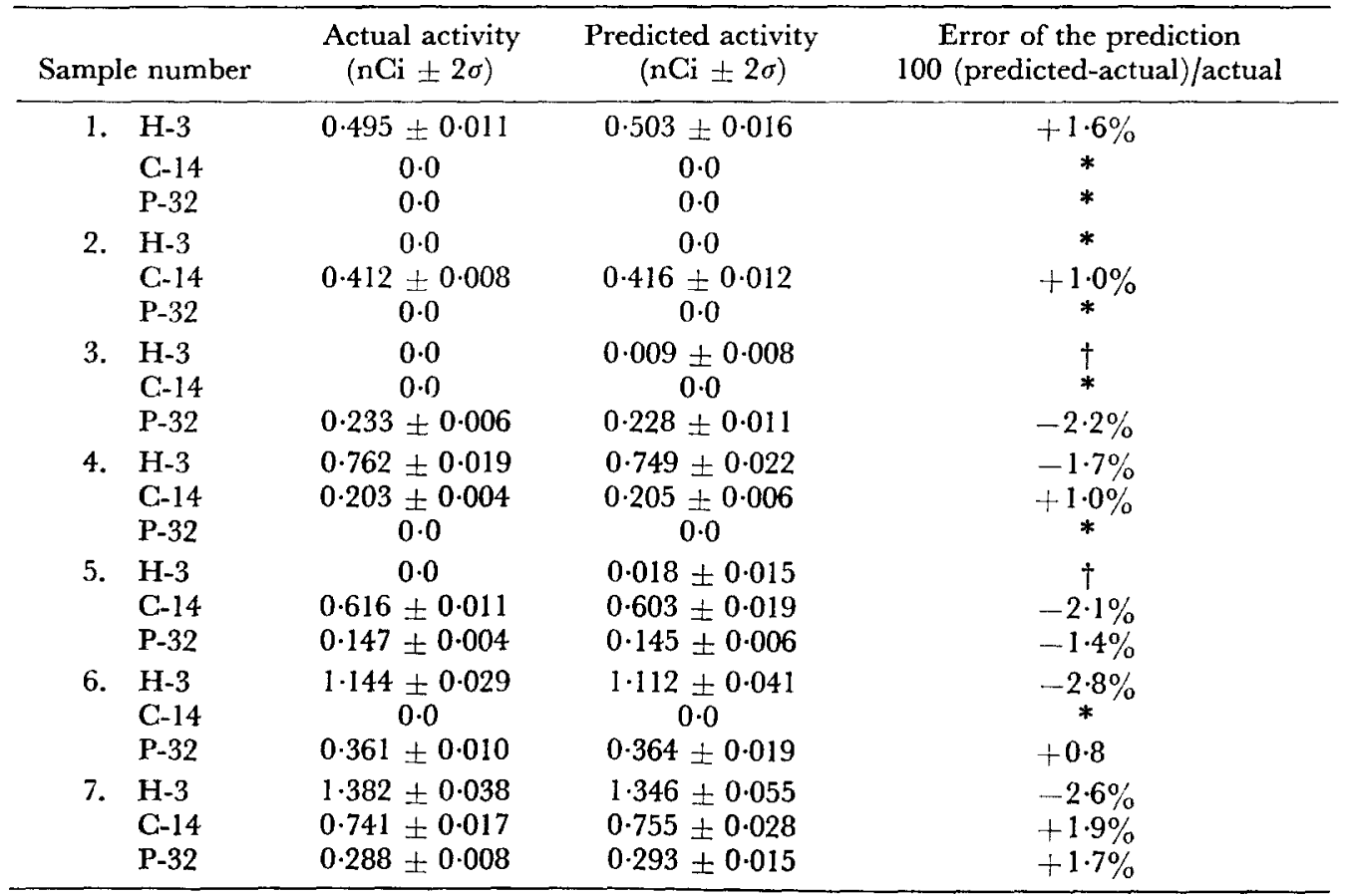

* No activity was predicted when none was present in the sample.

$\dagger$ Some activity was predicted when none was present in the sample.

that were obtained from these analyses. The results are in good agreement with the known concentrations present.

\section{SUMMARY}

A method to record and analyze quantitatively beta spectra produced by samples that contain beta-emitting radionuclides has been developed. The method to record beta spectra developed in this investigation produces a single spectrum composed of three energy ranges which permits analyses of samples that contain beta emitters with widely differing energies. Tests have shown this method of beta spectrum analysis to be a rapid and an accurate method to analyze samples that contain mixtures of tritium, carbon- 14 and phosphorus- 32 in various proportions. Further tests of the method are planned to determine the usefulness of the procedure for other beta emitters, minimum detectable concentrations, effects of quench, and limitations imposed by samples that contain radionuclides that emit both beta particles and gamma rays.
Acknowledgements-The authors wish to acknowledge their gratitude to Dr. G. HoYt WhIPple, Professor of Radiological Health, Dr. R. ICE, Associate Professor of Pharmacy, and Dr. W. L. Rogers, Research Associate, Department of Internal Medicine University of Michigan, for their advice and guidance in this investigation. The authors also wish to express their appreciation to the American Electric Power Service Corporation for financial support and the loan of the instrumentation used and to Packard Instrument Company for their cooperation and technical advice.

\section{REFERENCES}

1. Dougras G. S. (Ed.) Radioassay Procedures for Environmental Samples. U.S. Public Health Service Publication No. 999-RH-27, U.S. Government Printing Office, Washington, D.C. (January 1967).

2. KAHN B. et al. Radiological Surveillance Studies at a Pressurized Water Nuclear Power Reactor. U.S. Environmental Protection Agency, National Environmental Research Center, Cincinnati, Ohio (August 1971). 